\title{
Análise de concepções e visões de professores de ciências sobre educação ambiental
}

\author{
Ana Lucia Gomes Cavalcanti Neto ${ }^{1}$ \\ Edenia Maria Ribeiro do Amaral 2
}

Resumo: Este trabalho teve como objetivo analisar concepções sobre Educação Ambiental apresentadas por professores de Ciências do Ensino Fundamental e avaliar perspectivas de Educação Ambiental evidenciadas quando esses professores descrevem a abordagem de temas ambientais em suas aulas. Para isso foi aplicado um questionário a 12 professores de Ciências do município de Escada/PE e as respostas foram analisadas a partir da cartografia proposta por Sauvé (2005). Um percentual relevante desses professores apresentou ideias vagas sobre Educação Ambiental, o que sugere a ausência de uma concepção estruturada; outros revelaram concepções conservacionistas e críticas de Educação Ambiental. Os dados indicam que majoritariamente os professores parecem relacionar a formação para a cidadania ambiental a uma perspectiva conservacionista do ambiente quando declaram realizar atividades didáticas nas quais os alunos são apenas espectadores e executores de tarefas preestabelecidas. Esse tipo de postura contraria abordagens inovadoras apontadas pela literatura sobre a Educação Ambiental na escola.

Palavras-chave: Concepções de professores. Cidadania ambiental. Ação didática.

\section{Analysis of science teachers' conceptions and views on environmental education}

Abstract: This work aimed to analyze conceptions presented by Science teachers on Environmental Education and to evaluate perspectives on Environmental Education which emerge when such teachers describe how they approach environmental issues in their classes. In order to do that, we applied a questionnaire to 12 Science teachers in the city of Escada (PE), Brazil, and we analyzed their answers based on the cartography proposed by Sauvé (2005). Data analysis showed a significant percentage of teachers stating vague ideas about Environmental Education, which suggests a lack of structured conceptions, whereas others showed conservationist and critical views on Environmental Education. Data also indicate that most of the teachers seem to relate environmental citizenship education to a conservationist view on environment when they state that they perform instructional activities in which students are only spectators of planned tasks. This kind of posture goes in opposition to innovative approaches proposed in the literature which discusses Environmental Education in the school.

Keywords: Teachers' conceptions. Environmental citizenship. Instructional action.

1 Professora da Educação Básica, Escada/PE. analuneto@gmail.com

2 Professora do PPG em Ensino de Ciências da UFRPE, Recife/PE. edsamaral@uol.com.br 


\section{Introdução}

Neste trabalho apresentamos uma análise de concepções de Educação Ambiental de professores de Ciências do município de Escada/PE. O objetivo é avaliar perspectivas de Educação Ambiental que estão sendo evidenciadas quando os professores dizem trabalhar com temas ambientais e que estratégias didáticas são apontadas por esses professores para o trabalho com esses temas em aulas de Ciências.

Diante desse propósito, consideramos importante refletir sobre a questão ambiental que emerge no momento atual, quando são colocados grandes desafios à sobrevivência da espécie humana e das demais no planeta. São feitos debates sobre as questões ambientais em diferentes instâncias - científica, econômica, social e política - e neles são abordadas as ameaças à sustentabilidade do nosso planeta Terra, considerando a perda de um equilíbrio ambiental, que parece vinculada às formas de organização humana, que muitas vezes promovem desigualdades econômicas, sociais, culturais, injustiças e violência. Tudo isso parece ser causa e consequência de um empobrecimento ético e humano que é mantido e agravado por um processo educacional que, em geral, não busca conscientizar crianças, jovens e adultos sobre os graves efeitos da depredação e mau uso do ambiente e recursos advindos do mesmo.

Segundo Morin (2003), esta é uma crise de valores que tem suas raízes na ciência moderna, detentora do paradigma racionalista, através do qual aprendemos a pensar o mundo de uma perspectiva dualista: natureza/cultura, corpo/mente, sujeito/objeto, razão/emoção. Nesse cenário, na medida em que o mundo natural foi afastado da cultura e a valorização da diversidade deu lugar à busca pela universalidade do conhecimento, os fenômenos culturais foram limitados às determinações das leis naturais gerais. Isso resultou em uma postura na qual o ser humano tenta se colocar como centro e todas as outras partes que compõem o ambiente estivessem a seu dispor (GUIMARÃES, 2005).

No que concerne especificamente à questão ambiental, na medida em que a sociedade foi evoluindo, se desenvolvendo e se tornando mais complexa, fomos perdendo o elo com a natureza e nos distanciando dela. Aos poucos foi sendo inscrita em nosso ideário ambiental a percepção da natureza como fenômeno estritamente biológico, independente, constituído em oposição ao mundo cultural. Diante da complexidade e imprevisibilidade dos problemas sociais e ambientais que ora vivenciamos, e da necessidade da construção de uma sociedade mais justa, solidária e humana, torna-se primordial superar essa percepção. É importante questionar a concepção de um mundo estritamente biológico das Ciências Naturais e ampliar essa visão a partir de uma concepção de mundo que inclui os valores culturais, o mundo das humanidades.

Nesse contexto de mudança, o processo educativo torna-se fator essencial e deve oportunizar experiências que discutam diferentes perspectivas, por exemplo, a percepção integrada de ambiente, na qual o ser humano compõe o todo da natureza, e não apenas parte isolada da mesma. De acordo com Guimarães (2005), ao assimilar essa visão (holística), a dominação do ser sobre o 
ambiente perde o seu valor, podendo resultar em atitudes tanto individuais como coletivas que possibilitarão uma "ação mais racional com o ambiente e capaz de responder às necessidades sociais" (DIAS, 1999, p. 107). O processo deve, assim, possibilitar aos indivíduos compreensão, sensibilização e ação que resultem na formação de uma consciência ecologicamente equilibrada sobre os modos de intervenção humana no ambiente.

É nesse contexto que se justificam os movimentos para uma Educação Ambiental, evidenciando-se características que possibilitam problematizar a ação humana e as consequencias trazidas ao ambiente pelos processos sociais e buscando-se levar as pessoas a pensarem que os recursos naturais não são infinitos. Isso pode contribuir para uma reflexão sobre o modelo civilizatório que vem sendo historicamente estabelecido e também pode nos ajudar a pensar em novas possibilidades de organização da vida no planeta.

De acordo com Carvalho (2006), a perspectiva ambiental enquanto ação educativa tem sido importante mediadora entre os campos de estudo educacional e ambiental. Como assinala Leff (2006, p. 217), a crise ambiental não é somente crise ecológica, mas é crise de razão, sendo as problemáticas ambientais problemas fundamentalmente de conhecimento. Tudo isso tem repercussões diretas na política ambiental, que deve passar por uma política do conhecimento, e na educação. Para o autor:

Apreender a complexidade ambiental exige a compreensão do conhecimento sobre o meio. [...] Implica não só no aprendizado de fatos novos (de maior complexidade); inaugura um saber que desconstrói os princípios epistemológicos da ciência moderna e funda uma nova pedagogia, por meio de uma nova racionalidade que significa a reapropriação do conhecimento a partir do ser do mundo e do ser no mundo; a partir do saber e da identidade que se forjam e se incorporam ao ser de cada indivíduo e de cada cultura. (LEFF, 2006, p. 217-219).

Trata-se de propiciar uma educação não para adaptar o homem ao meio, mas que possibilite o desenvolvimento da sua natureza criativa de modo que ele possa ser sujeito da sua história, guiado por uma nova racionalidade. Essa racionalidade deve ser conduzida não para uma cultura de desesperança e alienação, mas para uma cultura de emancipação, de humanização, que permita o surgimento de novas formas de reapropriação do mundo (LEFF, 2006).

Nessa perspectiva, a Educação Ambiental, que é vista como um processo que afeta o homem em sua totalidade, deve ser conduzida para possibilitar o desenvolvimento de atitudes e competências definidas, como: consciência, conhecimento, atitudes, aptidões, capacidade de avaliação e de ação crítica no mundo (MEDINA, 2003). O processo educativo, nesse cenário, deve contribuir para a formação de um pensamento crítico, criativo e conectado com a necessidade de propor respostas para o futuro, capaz de analisar as complexas relações entre os processos naturais e sociais e de atuar no ambiente em uma perspectiva global, respeitando as diversidades socioculturais. 
A expectativa de uma mudança social promovida por um processo educacional que possibilite a formação de sujeitos capazes de tomar decisões responsáveis em relação aos outros e ao ambiente está fortemente relacionada, de acordo com Leme (2006), às concepções de educação, ambiente e Educação Ambiental e dos valores de quem está mediando os processos formativos. Em se tratando de concepções a respeito de educação e ambiente, concordamos com Leme (2006) que existe uma relação de sinergia entre esses dois campos, o que se reflete nas propostas de Educação Ambiental. Considerando uma relação de influência mútua, a autora coloca que "é como um movimento paralelo", de forma que, ao ampliar o olhar sobre o papel da educação, a sociedade também amplia a compreensão sobre o ambiente e vice-versa. "A ampliação significa uma melhor apreensão da complexidade inerente a ambos, o que não quer dizer a compreensão da totalidade dos temas, mas a diminuição gradativa de uma visão reducionista" (LEME, 2006, p. 45). As ideias de Leme podem ser ampliadas pelos estudos realizados por Sauvé (2005) sobre abordagens da Educação Ambiental. Nesses estudos, apesar de a autora apontar a preocupação com o ambiente e o reconhecimento do papel central da educação para a melhoria da relação com o ambiente, pode-se perceber que são adotados diferentes discursos e diversas maneiras de conceber e de praticar a ação educativa nesse campo. Tais ideias podem ser analisadas no Quadro 1 a seguir, no qual a autora traçou uma cartografia de quinze principais correntes em Educação Ambiental, enfatizando os seguintes aspectos: concepção dominante de ambiente, intenção central da Educação Ambiental, enfoque privilegiado e estratégias que caracterizam as ações educativas.

Quadro 1. Diversidade de correntes em Educação Ambiental.

\begin{tabular}{|c|c|c|c|c|}
\hline Correntes & $\begin{array}{l}\text { Concepções } \\
\text { de ambiente }\end{array}$ & Objetivos da EA & $\begin{array}{c}\text { Enfoques } \\
\text { dominantes }\end{array}$ & $\begin{array}{c}\text { Exemplos de } \\
\text { estratégias }\end{array}$ \\
\hline Naturalista & Natureza & $\begin{array}{l}\text { Reconstruir uma } \\
\text { ligação com a } \\
\text { natureza }\end{array}$ & $\begin{array}{c}\text { Sensorial, } \\
\text { Experiencial, } \\
\text { Afetivo, Cognitivo, } \\
\text { Criativo e Estético }\end{array}$ & $\begin{array}{c}\text { Imitação, } \\
\text { Interpretação, } \\
\text { Jogos sensoriais, } \\
\text { Atividades de } \\
\text { descobertas }\end{array}$ \\
\hline $\begin{array}{l}\text { Conservacio- } \\
\text { nista/Recursiva }\end{array}$ & Recurso & $\begin{array}{c}\text { Adotar } \\
\text { comportamento de } \\
\text { conservação }\end{array}$ & $\begin{array}{l}\text { Cognitivo } \\
\text { Pragmático }\end{array}$ & $\begin{array}{l}\text { Guia ou códigos de } \\
\text { comportamentos }\end{array}$ \\
\hline Resolutiva & Problema & Resolver problemas & $\begin{array}{c}\text { Cognitivo } \\
\text { Pragmático }\end{array}$ & Estudo de casos \\
\hline Sistêmica & Sistema & $\begin{array}{l}\text { Desenvolver o } \\
\text { pensamento } \\
\text { sistêmico } \\
\end{array}$ & Cognitivo & Estudo de casos \\
\hline Científica & $\begin{array}{l}\text { Objeto de } \\
\text { estudos }\end{array}$ & $\begin{array}{c}\text { Adquirir } \\
\text { conhecimentos }\end{array}$ & $\begin{array}{l}\text { Cognitivo } \\
\text { Experimental }\end{array}$ & $\begin{array}{c}\text { Estudo de } \\
\text { fenômenos, } \\
\text { observação, } \\
\text { experimentação }\end{array}$ \\
\hline Humanista & Meio de vida & $\begin{array}{l}\text { Desenvolver um } \\
\text { sentimento de } \\
\text { pertença }\end{array}$ & $\begin{array}{l}\text { Sensorial } \\
\text { Cognitivo } \\
\text { Afetivo }\end{array}$ & $\begin{array}{l}\text { Estudo do meio } \\
\text { Leitura de } \\
\text { paisagem }\end{array}$ \\
\hline
\end{tabular}




\begin{tabular}{|c|c|c|c|c|}
\hline Feminista & $\begin{array}{l}\text { Objeto de } \\
\text { solicitude }\end{array}$ & $\begin{array}{c}\text { Integrar os valores } \\
\text { feministas à relação } \\
\text { com o meio } \\
\text { ambiente. }\end{array}$ & $\begin{array}{c}\text { Intuitivo } \\
\text { Afetivo } \\
\text { Simbólico } \\
\text { Espiritual } \\
\text { Criativo/Estético }\end{array}$ & $\begin{array}{l}\text { Estudo de casos } \\
\text { Oficinas de criação } \\
\text { Atividade de } \\
\text { intercâmbio de } \\
\text { comunicação. }\end{array}$ \\
\hline Etnográfica & $\begin{array}{c}\text { Território } \\
\text { Lugar de } \\
\text { identidade } \\
\text { Natureza/cultura }\end{array}$ & $\begin{array}{c}\text { Reconhecer a } \\
\text { estreita ligação entre } \\
\text { natureza e cultura }\end{array}$ & $\begin{array}{c}\text { Experiencial } \\
\text { Intuitivo } \\
\text { Afetivo } \\
\text { Simbólico } \\
\text { Espiritual } \\
\text { Criativo/Estético }\end{array}$ & $\begin{array}{c}\text { Contos, narrações e } \\
\text { lendas } \\
\text { Estudo de casos } \\
\text { Imersão } \\
\text { Modelização }\end{array}$ \\
\hline Ecoeducação & $\begin{array}{c}\text { Pólo de } \\
\text { interação para a } \\
\text { formação } \\
\text { pessoal } \\
\text { Cadinho de } \\
\text { identidade }\end{array}$ & $\begin{array}{l}\text { Construir uma } \\
\text { melhor relação com } \\
\text { o mundo }\end{array}$ & $\begin{array}{c}\text { Experiencial } \\
\text { Sensorial } \\
\text { Intuitivo } \\
\text { Afetivo } \\
\text { Simbólico } \\
\text { Criativo }\end{array}$ & $\begin{array}{l}\text { Relato de vida } \\
\text { Imersão } \\
\text { Exploração } \\
\text { Introspecção } \\
\text { Escuta sensível } \\
\text { Brincadeiras. }\end{array}$ \\
\hline Práxica & $\begin{array}{c}\text { Cadinho de } \\
\text { ação/reflexão }\end{array}$ & $\begin{array}{l}\text { Aprender em, para e } \\
\text { pela ação. } \\
\text { Desenvolver } \\
\text { competências de } \\
\text { reflexão }\end{array}$ & Práxico & Pesquisa-ação \\
\hline Crítica & $\begin{array}{l}\text { Objeto de } \\
\text { transformação, } \\
\text { Lugar de } \\
\text { emancipação }\end{array}$ & $\begin{array}{c}\text { Descobrir as } \\
\text { realidades } \\
\text { socioambientais } \\
\text { visando transformar } \\
\text { o que causa } \\
\text { problemas } \\
\end{array}$ & $\begin{array}{c}\text { Práxico } \\
\text { Reflexivo } \\
\text { Dialogístico }\end{array}$ & $\begin{array}{c}\text { Análise de discurso } \\
\text { Estudo de casos } \\
\text { Debates } \\
\text { Pesquisa-ação. }\end{array}$ \\
\hline $\begin{array}{c}\text { Projeto de } \\
\text { desenvolvimen- } \\
\text { to sustentável }\end{array}$ & $\begin{array}{c}\text { Recursos para o } \\
\text { desenvolvimento } \\
\text { econômico }\end{array}$ & $\begin{array}{c}\text { Promover um } \\
\text { desenvolvimento } \\
\text { econômico } \\
\text { respeitoso dos } \\
\text { aspectos sociais e do } \\
\text { meio ambiente }\end{array}$ & $\begin{array}{c}\text { Pragmático } \\
\text { Cognitivo }\end{array}$ & $\begin{array}{l}\text { Estudo de casos } \\
\text { Experiência de } \\
\text { resolução de } \\
\text { problemas } \\
\text { Projeto de } \\
\text { desenvolvimento de } \\
\text { sustentação e } \\
\text { sustentável. }\end{array}$ \\
\hline Moral/ ética & $\begin{array}{l}\text { Objeto de } \\
\text { valores }\end{array}$ & $\begin{array}{l}\text { Dar prova de } \\
\text { ecocivismo } \\
\text { Desenvolver um } \\
\text { sistema ético }\end{array}$ & $\begin{array}{l}\text { Cognitivo } \\
\text { Afetivo } \\
\text { Moral }\end{array}$ & $\begin{array}{l}\text { Análise de valores } \\
\text { Definição de } \\
\text { valores } \\
\text { Crítica de valores } \\
\text { sociais. } \\
\end{array}$ \\
\hline Holística & $\begin{array}{l}\text { Total } \\
\text { Todo } \\
\text { O Ser }\end{array}$ & $\begin{array}{c}\text { Desenvolver as } \\
\text { múltiplas dimensões } \\
\text { de seu ser em } \\
\text { interação com o } \\
\text { conjunto de } \\
\text { dimensões do meio } \\
\text { ambiente }\end{array}$ & $\begin{array}{l}\text { Holístico } \\
\text { Orgânico } \\
\text { Intuitivo } \\
\text { Criativo }\end{array}$ & $\begin{array}{c}\text { Exploração livre } \\
\text { Visualização } \\
\text { Oficinas de criação } \\
\text { Integração de } \\
\text { estratégias } \\
\text { complementares. }\end{array}$ \\
\hline Biorregionalista & $\begin{array}{l}\text { Lugar de } \\
\text { pertença }\end{array}$ & $\begin{array}{c}\text { Desenvolver } \\
\text { competências em } \\
\text { ecodesenvolvimento } \\
\text { comunitário, local } \\
\text { ou regional }\end{array}$ & $\begin{array}{l}\text { Cognitivo } \\
\text { Afetivo } \\
\text { Experiencial } \\
\text { Pragmático } \\
\text { Criativo }\end{array}$ & $\begin{array}{c}\text { Exploração do } \\
\text { meio } \\
\text { Projeto comunitário } \\
\text { Criação de } \\
\text { ecoempresas }\end{array}$ \\
\hline
\end{tabular}

Fonte: Sauvé, 2005, p. 40-42.

A cartografia elaborada por Sauvé (2005) mostra uma variedade de práticas de Educação Ambiental materializada em variados contextos, o que resulta em finalidades diversificadas para o processo educativo, alcançadas a partir de 
distintos meios. Compreender esses contextos significa, portanto, esboçar o cenário em que se situa a formação ambiental.

A partir dos estudos de Sauvé (2005), consideramos que a promoção de uma ação educativa que possibilite mudança social e a formação de cidadãos com capacidade para participar na tomada de decisões de forma comprometida com as questões ambientais exige: a) uma proposta educativa centrada na conscientização, na mudança de atitudes e de práticas sociais, no desenvolvimento de competências para a avaliação e participação ativa dos educandos, com base em um pensamento crítico sobre o processo de educação ambiental; b) a definição de um posicionamento ético-político por parte dos mediadores de tal proposta. Nesse contexto, o processo educativo deve ser entendido como ato político no sentido amplo, isto é, como prática social cujo objetivo é a formação de sujeitos políticos, capazes de agir criticamente na sociedade (CARVALHO, 2006, p. 186). Portanto, mais do que comportamento, o processo educativo deve ser conduzido de modo a formar sujeitos da ação política. Para Carvalho (2006, p. 186), "a capacidade da ação política é a expressão mais acabada da condição humana".

Diante do exposto e desejando compreender como se configura a Educação Ambiental no âmbito específico das aulas de Ciências, neste trabalho analisamos concepções sobre Educação Ambiental apresentadas por professores do Ensino Fundamental II e avaliamos perspectivas de ações educativas e estratégias didáticas apontadas para o trabalho com temas ambientais.

A escolha dessa área de conhecimento está relacionada ao fato de percebermos, como pesquisadoras em Ensino de Ciências, lacunas entre a formação científica e a formação ambiental dos professores e, ao mesmo tempo, considerarmos que existem possibilidades de efetivação da Educação Ambiental na área de Ensino de Ciências. Tais perspectivas estão relacionadas a dois aspectos principais: o primeiro diz respeito à proximidade entre os fenômenos naturais - objeto de estudo da área de Ciências Naturais - e as questões ambientais - objetivo central da Educação Ambiental (MERGULHÃO, 1998). O segundo aspecto está relacionado com as convergências existentes entre propostas de Educação Ambiental e as atuais orientações curriculares para o Ensino de Ciências, que ressaltam os processos de alfabetização e/ou letramento científico voltados para uma formação cidadã, o que está evidenciado nos Parâmetros Curriculares Nacionais (BRASIL, 1998), principalmente quando é sugerido como tema transversal o Meio Ambiente.

Portanto, conhecer as concepções dos professores de Ciências sobre Educação Ambiental se configura não só como um dos pressupostos básicos para avaliar como vem se desenvolvendo a Educação Ambiental no contexto das salas de aula de Ciências mas também como um parâmetro norteador para o planejamento da formação continuada desses professores. Uma formação que busque superar visões reducionistas que dificultam e interferem na formação de uma consciência ambiental voltada para a sustentabilidade do planeta. 


\section{Metodologia}

Neste trabalho adotamos, articulada com o tratamento quantitativo de dados, uma abordagem metodológica qualitativa, na qual é privilegiada a dimensão interpretativa da análise (ANDRÉ, 2007). Este artigo é um recorte de estudo mais amplo sobre análise de estratégias didáticas utilizadas por professores de Ciências para o desenvolvimento de temas ambientais em aulas de Ciências e de Educação Ambiental (CAVALCANTI NETO, 2009), o qual foi desenvolvido como dissertação de mestrado. Os dados foram coletados no período de fevereiro a abril de 2008 com professores de Ciências do Ensino Fundamental II da rede municipal da cidade de Escada, Zona da Mata Sul de Pernambuco. Aqui será apresentada a análise feita a partir da aplicação de um questionário de perguntas abertas no qual buscamos levantar ideias dos professores acerca de questões ambientais.

As respostas ao questionário contribuíram para o conhecimento e análise do tipo de estratégias didáticas adotadas pelos professores quando afirmam estar envolvidos com alguma forma de Educação Ambiental nas escolas públicas da cidade de Escada. O posicionamento dos professores expresso no questionário também mostrou pistas para entendermos algumas dificuldades encontradas para a implantação de ações que visam a Educação Ambiental na escola e que pretendem contribuir para a formação do sujeito cidadão.

Para a aplicação do questionário foram realizados os seguintes procedimentos: solicitação de autorização à Secretária de Educação do Município da Escada para o desenvolvimento da pesquisa, aplicação do questionário aos professores e análise das respostas. Alguns questionários foram aplicados nas escolas, outros foram aplicados na própria residência do professor, todos com o acompanhamento da pesquisadora, porém, sem nenhuma interferência na elaboração das respostas. Participaram dessa etapa 12 professores que representavam 100\% dos professores de Ciências do Ensino Fundamental II efetivos da rede municipal, os quais serão aqui denominados por letras numeradas, de P1 a P12. Todos os professores investigados são licenciados em Ciências com habilitação em Biologia, sendo um deles especialista em Ciências Ambientais, sete, em Ciências Biológicas e quatro, em Ensino de Ciências e Biologia.

\section{Análise dos dados}

Para proceder à análise dos dados obtidos a partir da aplicação do questionário, foi construída uma tabela com as respostas apresentadas pelos professores investigados, as quais foram categorizadas em três grupos. No primeiro grupo estão as respostas para as questões 1 e 2 , nas quais buscamos identificar, com base na cartografia proposta por Sauvé (2005), as concepções sobre Educação Ambiental apresentadas pelos professores. As correntes se referem à forma geral como são concebidos os processos e as práticas de Educação Ambiental. Nos resultados, foram encontradas ideias que convergem 
para as correntes: conservacionista, crítica social, moral/ética, holística e humanista. As respostas que não se enquadraram em nenhuma das correntes apresentadas e descritas por Sauvé foram incluídas na categoria "indefinida", por apresentarem ideias confusas e pouco conectadas. Para identificar tipos de estratégias adotadas pelos professores quando afirmam estar envolvidos com alguma atividade de Educação Ambiental, na segunda etapa (questões 3 e 4) foram considerados aspectos descritos pelos professores com relação à forma de participação dos alunos em um processo de Educação Ambiental. Tomando por base os estudos de Diniz e Manzano (2003), consideramos três situações possíveis: a) atividades nas quais o aluno é predominantemente espectador; b) atividades nas quais o aluno é o executor de tarefas preestabelecidas, sem maior envolvimento ou reflexão sobre as mesmas; e c) o aluno é incentivado a construir conhecimentos que propiciem o desenvolvimento de habilidades e reflexões sobre situações reais.

Nas respostas às questões 5 e 6 , buscamos levantar facilidades e dificuldades apontadas pelos professores para a inserção de elementos de Educação Ambiental no contexto de sala de aula, bem como identificar o efetivo desenvolvimento de atividades consideradas pelos professores como estratégias de Educação Ambiental. Essa etapa nos possibilitou analisar as circunstâncias nas quais os professores investigados utilizam tais atividades.

\section{Resultados e discussão}

Os resultados serão apresentados a partir da categorização e discussão das respostas analisadas para cada questão proposta.

Questão 1 - O que você pensa sobre Educação Ambiental?

A análise das respostas mostrou que 25\% dos professores apresentaram uma concepção conservacionista de Educação Ambiental, ou seja, uma visão na qual o ensino está focado na adoção de um comportamento de conservação dos recursos naturais por parte dos alunos, ou seja, trata-se de uma educação para a conservação. Podemos perceber isso nas seguintes afirmações:

[...] uma educação para que as pessoas fossem educadas para fazer conservação [...]. [...] todo mundo também deveria plantar uma árvore, pois ajudaria o ambiente a ficar mais saudável. (P10).

Eu penso educação ambiental como sendo algo essencial na vida do ser humano, já que tem como finalidade preservar o que é necessário para a sobrevivência. (P12).

Outros 25\% dos professores apresentaram respostas como esta: "Segmento da educação que visa a formação de um indivíduo crítico, criativo e transformador da sociedade, que reflita sobre o presente e encontre estratégias de sobrevivência para as próximas gerações através do desenvolvimento 
sustentável" (P4), que converge para a corrente da crítica social, inspirada no campo da teoria crítica, com um componente necessariamente político. Nessa visão, o ensino deve ser voltado para a transformação de realidades e no seu curso emergem projetos de ação em uma perspectiva de emancipação e de libertação das alienações. Um percentual de 16,7\% dos professores apresentou ideias próximas a concepções presentes na corrente moral/ética, que busca o desenvolvimento do sistema ético por parte dos envolvidos no processo educacional. Podemos destacar essa corrente na concepção de P3 ao afirmar que Educação Ambiental é "algo importante que possibilita aos jovens ter conhecimento dos fatos e da responsabilidade que cada um tem com o meio ambiente". Finalmente, 33,3\% dos professores, apesar de reconhecerem a Educação Ambiental como um processo importante e que deve ser incluído no currículo das escolas e de outros espaços educativos não formais, não deixaram evidente em que visão estariam inseridas suas concepções. Respostas tais como "algo que deve ser inserido no currículo" (P2); "importante para o ensino em todos os aspectos" (P6); "de vital importância nos dias de hoje e deve ser vivenciada: nas escolas, nas indústrias, sindicatos, associações, governo, etc." (P7); "de grande importância na educação, é através dela que tentaremos fazer um país melhor, ou quem sabe, um mundo melhor" (P8), levaram-nos a constituir uma categoria chamada "indefinida", por não se encaixarem em qualquer das correntes apresentadas e não possuírem uma coerência própria para a proposição de novas categorias. A Figura 1 ilustra esses resultados.

Figura 1. Concepções de Educação Ambiental.

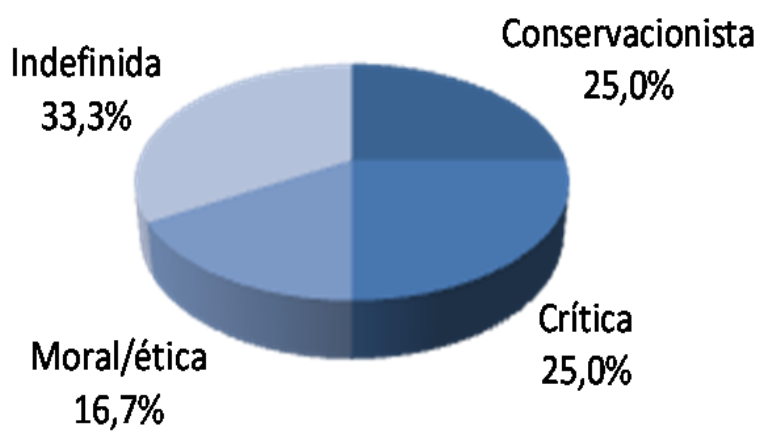

Diante desses resultados podemos inferir que, apesar de haver uma concepção crítica de Educação Ambiental por parte de alguns professores (percentual igual foi encontrado para a concepção conservacionista), um quantitativo significativo de professores ainda não apresenta uma concepção formada sobre Educação Ambiental. As respostas apresentadas por este último grupo expressam ideias sobre algo importante mas desconhecido para os investigados. A partir da proposição de que nossas concepções podem guiar nossas ações, uma vez que elas são os ângulos parciais que usamos para acessar o mundo (CARVALHO, 2006), os dados apontam uma necessidade de 
investimento na formação específica de professores de Ciências para que possam atuar na Educação Ambiental.

Questão 2-O que significa educar para a cidadania ambiental?

$\mathrm{Na}$ análise das respostas à questão 2, adotamos as mesmas categorias da questão anterior. Apesar do caráter indutivo que o termo cidadania ambiental apresenta, foram identificadas concepções diversas: 66,7\% dos professores apresentaram uma concepção conservacionista no que diz respeito à educação para a cidadania ambiental. Tal classificação foi realizada a partir da análise de afirmações como: "preparar o cidadão para um futuro promissor, educando e disciplinando para preservar o que temos na terra" (P3) e "educar para os cuidados com o meio ambiente" (P5). Um percentual de 8,33\% dos professores investigados demonstrou ter uma consciência ambiental que toma por base aspectos da corrente crítica social, ou seja, para eles, educar para a cidadania ambiental implica a formação de um indivíduo crítico e consciente das suas responsabilidades e dos seus direitos com relação ao ambiente e à sociedade. Tal concepção pode ser identificada na seguinte afirmação: "educar para a cidadania ambiental é trabalhar conceitos, informações atuais que ajudem a refletir e a formar comportamentos, a fim de decidir e atuar na realidade socioambiental, comprometendo-se com a vida, com o bem estar de cada um e da sociedade" (P1). A concepção próxima daquela aceita na corrente humanista está representada por um percentual de $8,33 \%$ dos professores investigados. Para nós, essa percepção ficou evidenciada em afirmações como:

[...] contribuir para a formação de pessoas conscientes de seu papel no ambiente em que está inserido. O homem é um ser histórico e cultural, ele precisa entender que a nossa vida (qualidade de vida) depende da relação que estabelecemos com o meio ambiente em que vivemos. Nós evoluímos junto com todos os outros componentes do ambiente, logo, fazemos parte desse ambiente. (P10).

Entre os demais investigados, 8,33\% apresentaram uma concepção próxima daquela encontrada na corrente holística e 8,36\% apresentaram concepções confusas, tais como: "é de suma importância para que tenhamos conhecimento no assunto e levarmos para dentro da sala de aula e praticarmos de verdade", o que não possibilitou uma caracterização específica. Os dados da questão 2 estão representados na Figura 2. 
Figura 2. Educação para a cidadania ambiental.

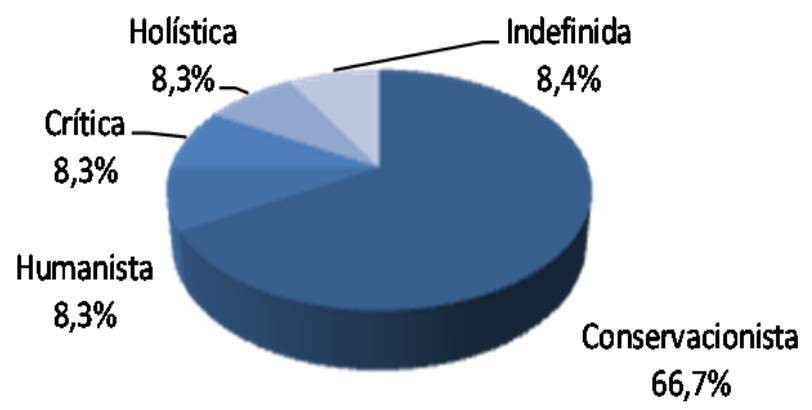

Como podemos perceber a partir da análise dos resultados das duas primeiras questões, um percentual significativo de professores demonstrou uma visão conservacionista de Educação Ambiental. Mesmo aqueles que na questão 1 expressaram ideias inseridas no que consideramos como uma visão crítica revelaram na questão 2 que parecem entender que a formação de uma cidadania ambiental pode ser feita em uma perspectiva conservacionista de educação. Essa corrente de pensamento, segundo Sauvé (2005), está inserida no programa de Educação Ambiental centrado nos três "R" (Redução, Reutilização e Reciclagem), o qual, apesar de ter também projetos coletivos como proposta de ação, na prática, segundo a autora, é voltado para a formação de comportamentos individuais. Uma proposta que privilegia apenas comportamentos individuais dificulta a formação de sujeitos capazes de tomar decisões responsáveis em relação aos outros e ao ambiente (LEME, 2006). Os resultados nos levam ainda a evidências de que o percentual significativo de professores que não apresentaram ideia clara sobre o que é Educação Ambiental (questão 1) pode estar relacionado ao fato de esses professores entenderem que a formação da cidadania ambiental é realizada num contexto diferente daquele do processo de Educação Ambiental (por exemplo, por campanhas de órgãos governamentais ou ONGs que não necessariamente atuam no contexto da educação formal).

Questão 3 - O que podemos fazer, na sala de aula, para a transformação de hábitos e práticas sociais e para a formação de uma cidadania ambiental?

Nas respostas, verificamos que: $41,6 \%$ dos professores acreditam poder contribuir para a formação de hábitos e práticas sociais e constituir posturas de uma cidadania ambiental realizando atividades nas quais o aluno é predominantemente espectador (assistir a noticiários, ler jornais e revistas, receber orientação sobre conservação, assistir a vídeos, palestras etc.); $25 \%$ dos professores investigados demonstraram acreditar na mudança de hábitos e atitudes a partir da realização de atividades em que o aluno é o executor de 
tarefas, sem necessariamente haver envolvimento com situações reais (pesquisas sobre os cuidados com o meio); $25 \%$ acreditam que a mudança de hábitos e atitudes pode ocorrer a partir de atividades que incentivem o desenvolvimento de habilidades e reflexões sobre situações reais em projetos interdisciplinares; e, finalmente, 8,4\% apresentaram ideias vagas, incluídas, portanto, na categoria "outros". Esses dados estão coerentes com as concepções apresentadas pelos professores nas duas primeiras questões, quando a maior parte deles mostrou acreditar que a formação de sujeitos críticos e participativos pode ocorrer pela conscientização sobre a conservação/preservação do ambiente. Isso se traduz na prática docente, na sala de aula, quando são propostas atividades didáticas em que os alunos participam apenas como espectadores. Esses resultados sugerem que as concepções pedagógicas dos professores podem estar próximas daquelas que valorizam o modelo bancário da educação, em que os conhecimentos são recebidos passivamente pelo aluno (FREIRE, 2007). Esse modelo de educação, que tem como propósito a adaptação do homem ao meio, potencialmente exclui a possibilidade de desenvolvimento da natureza criativa do aluno e tem como consequência sua alienação. Para Freire, um processo educativo que permita o surgimento de novas formas de reapropriação do mundo (LEFF, 2006) precisa ser guiado por uma cultura de emancipação, de humanização, que é possível quando o ensino é mediado por práticas que problematizam as situações reais dos estudantes. Os dados encontram-se representados na Figura 3.

Figura 3. Natureza das práticas para a formação da cidadania ambiental.

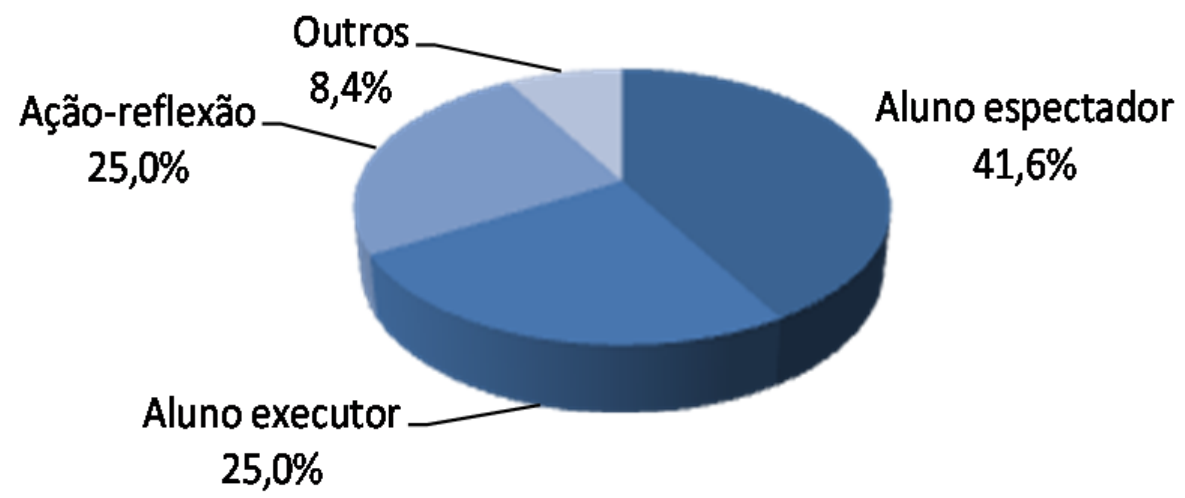

Questão 4 - De que forma as atividades relativas à Educação Ambiental podem ser inseridas nas suas aulas?

$\mathrm{Na}$ análise das respostas à questão 4 usamos a categorização feita para a questão anterior. Ao descreverem os tipos de atividades propostas para a Educação Ambiental, os professores parecem ampliar as nossas possibilidades de interpretação das suas posturas. Quarenta e um vírgula seis por cento $(41,6 \%)$ deles indicaram que a Educação Ambiental na sala de aula deve possibilitar aos alunos espaços de observação e reflexão da realidade local, estudos de casos, 
elaboração de projetos de intervenção na comunidade, sensibilização da comunidade escolar para mudanças de atitudes e busca de alternativas viáveis e ecologicamente corretas, além de pesquisas e coletas de dados, entre outros. Essas respostas foram inseridas na terceira situação possível de participação do aluno no processo de Educação Ambiental apresentada por Diniz e Manzano (2003), na qual o aluno é incentivado a construir conhecimentos que propiciem o desenvolvimento de habilidades e reflexões sobre situações reais. Nessa situação, os alunos poderiam desenvolver ações-reflexões sobre as tarefas realizadas. Trinta e três vírgula quatro por cento $(33,4 \%)$ dos professores apontaram atividades que se enquadram na categoria de aluno espectador (orientação para ver noticiários de TV, aulas expositivas de conscientização, exibição de vídeos, entre outras). Para 25\% dos professores, as atividades de Educação Ambiental devem ser inseridas de forma que o aluno possa executar tarefas (produzir cartazes, apresentar o conteúdo para os colegas, plantar mudas de árvores etc.), conforme explicitado na Figura 4 a seguir.

Figura 4. Formas de inserção de atividades de EA na sala de aula.

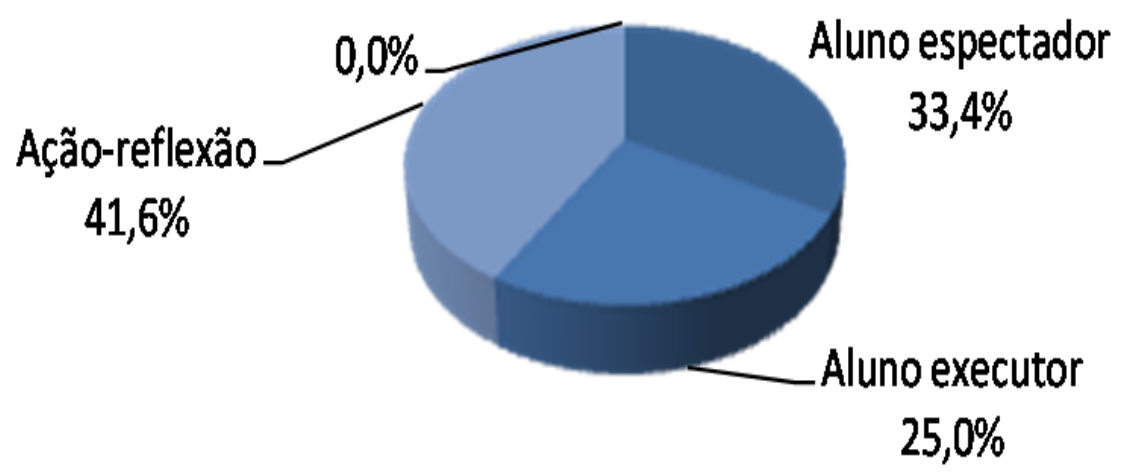

Dessa forma, ao analisarmos as atividades propostas pelos professores, verificamos um aumento no percentual de professores que apontam para uma ação de formação crítica da cidadania ambiental. No entanto, é importante ressaltar que, para alguns deles, os tipos de atividades propostas devem estar diretamente relacionados ao que eles acreditam que pode ser feito em sala de aula, e não necessariamente ao que eles fazem no cotidiano da sala de aula.

Outro ponto a ressaltar é que podemos perceber, pela análise das questões 3 e 4, que parece haver confusão quanto à compreensão dos objetivos da Educação Ambiental quando as respostas sugerem que o professor percebe o processo de formação da cidadania ambiental dissociado do processo de Educação Ambiental. Nesse contexto, os dados levantados nos permitem fazer a seguinte indagação: se a maioria dos professores investigados sabe apontar atividades adequadas à proposta de formação de sujeitos críticos dotados de uma cidadania ambiental, como isso ocorre se os mesmos parecem compreender a Educação Ambiental numa perspectiva conservacionista de ambiente (questão 
1)? Investir em programas de formação voltados para a cidadania ambiental não seria uma das formas de possibilitar uma prática educativa nos moldes da Educação Ambiental proposta por Carvalho (2006), Dias (1999), Leff (2006), Medina (2003), entre outros? A resposta para tais inquietações depende da implantação de uma política de formação continuada dos professores da rede municipal da cidade de Escada e um acompanhamento sistemático das práticas docentes e das respostas dos alunos a esse processo de formação.

Questão 5 - Você considera que seria fácil/simples inserir elementos de uma Educação Ambiental na sua sala de aula? Quais seriam as facilidades e/ou dificuldades?

As respostas à questão 5 mostram que $41,6 \%$ dos professores investigados afirmaram ser fácil inserir elementos de Educação Ambiental na sala de aula, ao passo que 58,4\% responderam ser essa uma tarefa difícil. Podemos arrolar alguns dos motivos que levam os professores a acreditarem na facilidade ou dificuldade dessa tarefa a partir de suas próprias afirmações. Entre as dificuldades citadas, destacamos:

[...] difícil é fazer os alunos mudarem hábitos já formados. (P1).

[...] a falta de aparelhamento das Escolas, capacitação do professor dentro da área e suporte financeiro para o professor. (P3).

[...] falta de interação entre as disciplinas, resistência dos professores em considerar que EA é de responsabilidade exclusiva do professor de Ciências. (P4).

Diante das respostas apresentadas podemos perceber que para uma parcela dos professores investigados a dificuldade de inserir elementos de Educação Ambiental está sempre relacionada ao outro ou a uma condição externa. Apesar de concordarmos que os elementos apontados pelos professores são necessários à efetivação da Educação Ambiental no processo educativo, tais dados nos permitem refletir novamente sobre a necessidade de uma formação continuada desses professores pautada pela perspectiva da construção de uma cidadania ambiental por parte de todas as instâncias envolvidas no processo educativo.

Ainda em relação às dificuldades, ao afirmar: "Considero difícil porque não tivemos uma educação para o ambiente, precisamos de subsídios para tal. Vivemos no mundo capitalista e tudo é voltado para isso: a educação, a mídia, a economia. Isso não quer dizer que eu não acredite na Educação Ambiental como promotora de qualidade de vida. A dificuldade é justamente porque o fundamento da educação não é para o ambiente e sim para o capitalismo. É preciso uma mudança nesse sentido" (P10), a professora levanta questões importantes sobre a relação educação-sociedade, o que nos faz refletir sobre a urgência da materialização de uma Educação Ambiental Crítica. Esta tem como objetivo "descobrir as realidades socioambientais visando transformar o que 
causa problemas" (SAUVÉ, 2005) e, de acordo com a autora, nessa corrente o ambiente é tomado como objeto de transformação, lugar de emancipação. Tal entendimento nos direciona a fortalecer a ideia de uma formação continuada que privilegie um modelo de Educação Ambiental pautado por atividades que promovam a ação-reflexão sobre temas ambientais pelos alunos.

Quanto às facilidades, os professores investigados apresentaram as seguintes justificativas:

[...] fácil por existir uma infinidade de formas. (P1).

[...] porque se refere praticamente ao dia a dia do aluno (queimada, desmatamento). (P2).

[...] fácil porque a juventude quer ter mais conhecimento sobre EA. Facilidade pelo fato de tratar de assuntos de interesse do aluno, retratar sua realidade e lhe colocar na condição de autor e não espectador. (P3).

[...] é fácil, pois mesmo que não tenha a disciplina de EA, podemos trabalhar a disciplina Ciências. (P4).

[...] é fácil através de seminários, debates, produção de textos, cartazes, frases, de palestras e passeatas para juntos encontrarmos soluções. (P6).

[...] é fácil, através de vídeos, DVD, trabalhos em grupo e pesquisa. (P7).

[...] à medida que você está transmitindo o assunto você já está trabalhando Educação Ambiental, principalmente porque trabalho a partir da realidade dele. (P11).

[...] quando falamos de algo que faz parte do nosso dia-a-dia é mais interessante participar. (P12).

Como podemos observar, ao se tratar de facilidades, parte dos professores investigados apresenta justificativas que contradizem as dificuldades apontadas. Esse dado nos faz pensar que existe, por parte desse professores, uma insegurança sobre os princípios que norteiam a Educação Ambiental e nos aponta mais uma vez a necessidade de investimento em formação continuada.

Questão 6 - Você teve alguma experiência com atividades em Educação Ambiental na sua sala de aula ou na sua escola? Se afirmativo, descreva resumidamente essa(s) experiência(s).

A maioria dos professores investigados demonstrou ter desenvolvido alguma atividade de Educação Ambiental em suas salas de aula ou na escola. Todavia, é importante ressaltar que tais experiências foram vivenciadas de forma esporádica, por meio da participação em eventos relacionados a datas comemorativas e/ou programas governamentais. Entre as atividades citadas estavam presentes: 
exposição de vídeo sobre impactos ambientais, plantio de mudas no pátio da escola, projeto adote uma árvore, plantio de sementes, projetos sobre o lixo do bairro com entrega de panfletos, palestras, exposição pelos alunos de problemas ambientais, entre outras. Essas respostas demonstram a ausência de um trabalho permanente de Educação Ambiental no contexto escolar, haja vista a realização das atividades apontadas pelos professores apresentar caráter pontual, sendo essas atividades desenvolvidas sem previsão de continuidade, além de, em sua maioria, não serem direcionadas para a transformação da realidade numa perspectiva de emancipação, de libertação das alienações. É importante salientar ainda que as dificuldades apontadas pelos professores na questão 5 refletem um número reduzido de atividades com temáticas ambientais desenvolvidas na sala de aula.

\section{Considerações finais}

A partir dos resultados obtidos, podemos perceber que, apesar de encontrarmos evidências de que alguns professores desenvolvem atividades que possibilitam a formação de um aluno capaz de analisar a realidade e intervir nela de forma crítica (ver Figura 4), parece não haver uma relação entre a proposição de tais atividades com um processo consciente de Educação Ambiental (Figura 3). Outras atividades descritas pelos professores parecem limitar a participação do aluno a uma postura de espectador ou executor de atividades que parecem não favorecer a formação de valores, comportamentos e atitudes necessárias para a construção de uma nova postura perante a atual problemática ambiental. Um ponto parece estar bem colocado: os tipos de atividades propostas pelos professores para uma Educação Ambiental estão relacionados tanto com as concepções que eles têm sobre a Educação Ambiental e a formação da cidadania ambiental como com as concepções gerais sobre educação e formas de ensinar construídas em outros contextos ou situações diferentes daqueles relacionados à Educação Ambiental.

A análise do primeiro bloco de questões mostrou que a maior parte dos investigados privilegia práticas comportamentalistas na EA. De acordo com Carvalho (2006), tais práticas não possibilitam ao sujeito a condição de agir e interferir no contexto em que está inserido, uma vez que são alimentadas pela concepção de sujeito atomizado, que se modela aos padrões preestabelecidos e age de forma que consiga a melhor adaptação possível. Uma prática que busca a formação de comportamentos padronizados privilegia estratégias didáticas em que o sujeito é predominantemente espectador (DINIZ; MANZANO, 2003). Isso está implicado com uma concepção passiva de cidadania ambiental, na qual o comportamento substitui a ação como principal forma de atividade humana (CARVALHO, 2006).

Acreditamos que o processo de Educação Ambiental Crítica pode se configurar como um dos caminhos possíveis para o empoderamento de indivíduos em relação às questões socioambientais, haja vista o pressuposto de formação de um sujeito crítico e transformador da realidade. Nesse sentido, 
entendemos que a construção de um processo de Educação Ambiental Crítica implica a formação de professores com uma visão educacional voltada para o processo de humanização e que tem como objetivo maior contribuir para a inserção social crítica e transformadora dos sujeitos no mundo. Concordamos com Carvalho (2006) que uma visão ingênua e bem intencionada de respeito à natureza não seria premissa suficiente para fundamentar uma ação educativa voltada para a intervenção na realidade socioambiental.

Finalmente, verificamos que muitas das dificuldades apontadas pelos professores com relação à Educação Ambiental referem-se ao contexto educacional do município em foco, as quais não são diferentes, em maior ou menor escala, daquelas encontradas em outros municípios do país. A superação dessas dificuldades, em nível local ou nacional, demanda ações que vão desde a otimização de infraestrutura nas escolas até a valorização profissional dos docentes, o que inclui programas de formação bem estruturados e com objetivos bem definidos.

\section{Referências}

ANDRÉ, Marli Eliza Dalmazo Afonso de. Etnografia da prática escolar. 13. ed. Campinas: Papirus, 2007.

BRASIL. Ministério da Educação. Secretaria de Educação Fundamental. Parâmetros Curriculares Nacionais: temas transversais. Brasília: Ministério da Educação, 1998.

CARVALHO, Isabel Cristina de Moura. Educação ambiental: a formação do sujeito ecológico. 2. ed. São Paulo: Cortez, 2006.

CAVALCANTI NETO. Ana Lucia Gomes. Educação Ambiental e Ensino de Ciências: uma análise de estratégias didáticas no nível fundamental. 2009. 157 f. Dissertação (Mestrado em Ensino de Ciências) - Universidade Federal Rural de Pernambuco, Recife, 2009.

DIAS, Genebaldo Freire. Atividades interdisciplinares de educação ambiental. São Paulo: Global, Gaia, 1999.

DINIZ, Renato Eugenio da Silva; MANZANO, Maria Anastácia. A temática ambiental nas séries iniciais do ensino fundamental: conversando com as professoras sobre as atividades realizadas. In: ENCONTRO NACIONAL DE PESQUISA EM EDUCAÇÃO EM CIENCIAS, 4., 2003, Bauru. Anais... Bauru: USP, 2003. p. 1-12.

FREIRE, Paulo. Educação e mudança. Tradução de Moacir Gadotti e Lílian Lopes Martins. 30. ed. Rio de Janeiro: Paz e Terra, 2007.

GUIMARÃES, Mauro. A dimensão ambiental na educação. 7. ed. Campinas: Papirus, 2005.

LEFF, Enrique. Epistemologia ambiental. Tradução de Sandra Valenzuela. 4. ed. São Paulo: Cortez, 2006.

LEME, Taciana Neto. Os conhecimentos práticos dos professores: (re)abrindo caminhos para a educação ambiental na escola. São Paulo: Annablume, 2006. 
MEDINA, Naná Mininni. Educação ambiental: uma metodologia participativa de formação. 3. ed. Petrópolis: Vozes, 2003.

MERGULHÃO, Maria Cornélia. Zoológico: uma sala de aula viva. 1998. 143 f. Dissertação (Mestrado em Educação) - Faculdade de Educação, Universidade de São Paulo, São Paulo, 1998.

MORIN, Edgar. Os sete saberes necessários à educação do futuro. Tradução de Catarina Eleonora F. da Silva e Jeanne Sawaya. 8. ed. São Paulo: Cortez, 2003.

SAUVÉ, Lucie. Uma cartografia das correntes em educação ambiental. Tradução de Ernani Rosa. In: SATO, Michèle; CARVALHO, Isabel Cristina de Moura (Org.). Educação ambiental: pesquisa e desafios. Porto Alegre: Artmed, 2005. cap. 1, p. 17-44. 